\title{
Non-medical use of prescription opioids is associated with heroin initiation among US veterans: a prospective cohort study
}

\author{
Geetanjoli Banerjee', E. Jennifer Edelman ${ }^{2,3}$, Declan T. Barry ${ }^{4,5}$, William C. Becker ${ }^{6}$, \\ Magdalena Cerdá7, Stephen Crystal ${ }^{8}$, Julie R. Gaither ${ }^{3,9}$, Adam J. Gordon ${ }^{10}$, Kirsha S. Gordon' ', \\ Robert D. Kerns ${ }^{6,12}$, Silvia S. Martins ${ }^{13}$, David A. Fiellin ${ }^{2,3}$ \& Brandon D. L. Marshall' \\ Department of Epidemiology, Brown School of Public Health, Providence, RI, USA,' Department of Internal Medicine, Yale School of Medicine, Yale University, New \\ Haven, CT, USA, ${ }^{2}$ Yale Center for Interdisciplinary Research on AIDS, Yale School of Public Health, Yale University, New Haven, CT, USA, ${ }^{3}$ Yale University School of \\ Medicine, New Haven, CT, USA, ${ }^{4}$ APT Foundation Pain Treatment Services, New Haven, CT, USA, ${ }^{5}$ Pain Research, Informatics, Multi-morbidities and Education \\ (PRIME) Center, VA, Connecticut Healthcare System, West Haven, CT, USA, ${ }^{6}$ Department of Emergency Medicine, University of California, Davis, Sacramento, CA \\ USA, Institute for Health, Health Care Policy, and Aging Research, Rutgers University, New Brunswick, NJ, USA, ${ }^{7}$ Yale Center for Medical Informatics, Yale School of \\ Medicine, New Haven, CT, USA, Center for Health Equity Research and Promotion (CHERP) \& Mental Illness Research Education and Clinical Center (MIRECC), \\ VA Pittsburgh Healthcare System and University of Pittsburgh, Pittsburgh, PA, USA, ${ }^{10}$ VA Connecticut Healthcare System, West Haven, CT, USA, ' Departments of \\ Psychiatry, Neurology and Psychology, Yale University, New Haven, CT, USA ${ }^{12}$ and Department of Epidemiology, Mailman School of Public Health, Columbia \\ University, New York, NY, USA ${ }^{13}$
}

\begin{abstract}
Aims To estimate the influence of non-medical use of prescription opioids (NMUPO) on heroin initiation among US veterans receiving medical care. Design Using a multivariable Cox regression model, we analyzed data from a prospective, multi-site, observational study of HIV-infected and an age/race/site-matched control group of HIVuninfected veterans in care in the United States. Approximately annual behavioral assessments were conducted and contained self-reported measures of NMUPO and heroin use. Setting Veterans Health Administration (VHA) infectious disease and primary care clinics in Atlanta, Baltimore, New York, Houston, Los Angeles, Pittsburgh and Washington, DC. Participants A total of 3396 HIV-infected and uninfected patients enrolled into the Veterans Aging Cohort Study who reported no life-time NMUPO or heroin use, had no opioid use disorder diagnoses at baseline and who were followed between 2002 and 2012. Measurements The primary outcome measure was self-reported incident heroin use and the primary exposure of interest was new-onset NMUPO. Our final model was adjusted for socio-demographics, pain interference, prior diagnoses of post-traumatic stress disorder and/or depression and self-reported other substance use. Findings Using a multivariable Cox regression model, we found that non-medical use of prescription opioids NMUPO was associated positively and independently with heroin initiation [adjusted hazard ratio $(\mathrm{AHR})=5.43,95 \%$ confidence interval $(\mathrm{CI})=4.01,7.35]$. Conclusions $\quad$ New-onset non-medical use of prescription opioids (NMUPO) is a strong risk factor for heroin initiation among HIV-infected and uninfected veterans in the United States who reported no previous history of NMUPO or illicit opioid use.
\end{abstract}

Keywords Heroin, longitudinal study, non-medical prescription drug use, opioid-related disorders, polysubstance use, veterans.

Correspondence to: Brandon Marshall, Department of Epidemiology, Brown University, 121 South Main Street, Providence, RI 02912, USA. E-mail: brandon_marshall@brown.edu

Submitted 24 December 2015; initial review completed 30 March 2016; final version accepted 9 June 2016

\section{INTRODUCTION}

Heroin use and opioid use disorders are serious public health problems [1]. The US Centers for Disease Control and Prevention (CDC) reported that the total number of heroin-attributable overdose deaths increased fivefold from 2001 to 2013, with 8257 heroin-related deaths in 2013 alone [2]. The substantial increase in heroin use and heroin-attributable overdose rates may be linked to the growth in sales, use and misuse of prescription opioids [3]. During the last decade, the number of opioid prescriptions dispensed in the United States increased by $48 \%$ [4,5]. Concomitantly, the non-medical use of prescription opioids (NMUPO) - defined operationally in the National Survey on Drug Use and Health as the use of prescription opioids 'without a prescription of the individual's own or 
simply for the experience or feeling the drugs cause'-is increasingly common [6]. The last 15 years has seen sharp rises in NMUPO [6-8], with 4.5 million individuals reporting NMUPO in the past month in 2013 [9]. Canadian data estimate that approximately $4.8 \%$ of the general population used prescription opioids non-medically in 2009 and as the demand for prescription opioids has increased so, too, has the availability of diverted prescription opioids [10]. In the past two decades, the use of opioids has also increased significantly in Europe [11]. In particular, there is a high prevalence of misuse of diverted opioids among drug-using populations in England and Scotland [11].

People who engage in NMUPO may be at a higher risk for transitioning to heroin use, in part because heroin has become more accessible and less expensive than prescription opioids in many US settings [12-14]. A nationally representative survey found that four out of five recent heroin initiates reported prior NMUPO, and the rate of heroin initiation among prior non-medical prescription opioid users was approximately 19 times greater than those who did not report non-medical use [15]. Heroin initiation is particularly troubling because of the additional risks associated with heroin use, including unknown purity and contaminants, overdose and injection-associated infections and vascular disease $[12,16]$. Transition from NMUPO to heroin also represents an increasingly prominent pathway leading to opioid-related mortality [17].

US military veterans represent a particularly high-risk population for illicit substance use and abuse [18-20]. Chronic pain is a significant problem among veterans [21], and is treated commonly with opioid analgesics [22]. Veterans also have high rates of mental health conditions that further increase the risk for NMUPO [23]. However, whether NMUPO plays a role in veterans' risk for initiating heroin use is poorly understood, particularly in those veterans from newer eras, including Operation Enduring Freedom and Operation Iraqi Freedom [24].

To address this critical public health problem, we examined the relationship between new-onset NMUPO and heroin initiation among veterans. We aimed to: (1) identify risk factors for heroin initiation among participants enrolled into the Veterans Aging Cohort Study; (2) calculate the crude incidence rate of heroin initiation in this high risk population; and (3) compare the hazard of heroin initiation between participants with self-reported NMUPO and no prior NMUPO.

\section{METHODS}

\section{Data sources}

This research utilizes data from the Veterans Aging Cohort Study (VACS); detailed data collection and survey methodology for VACS are described elsewhere [25-31]. The VACS is an ongoing, prospective cohort study of HIV-infected and uninfected veterans receiving medical care at eight Veterans Health Administration (VHA) sites located throughout the United States. Since June 2002, VACS has enrolled more than 7000 patients from the infectious disease or general medical clinics in Atlanta, Baltimore, Houston, Los Angeles, Pittsburgh, Washington DC and multiple sites in New York City. Participants in VACS are similar to other veterans receiving care within the VA, with the exception of participants being older and more predominantly black [30]. This comprehensive, longitudinal database contains variables from surveys completed approximately every 18 months, available from 2002 to 2012. The survey data are also linked to robust VA electronic medical records (EMR) containing data on prescribed medications, medical and substance use diagnoses and laboratory results for each patient. The VACS was approved by the institutional review boards at each participating VHA Medical Center and affiliated academic institutions.

\section{Participant eligibility}

The flow-chart illustrating the selection of eligible participants is illustrated in Fig.1. Of 7324 potentially

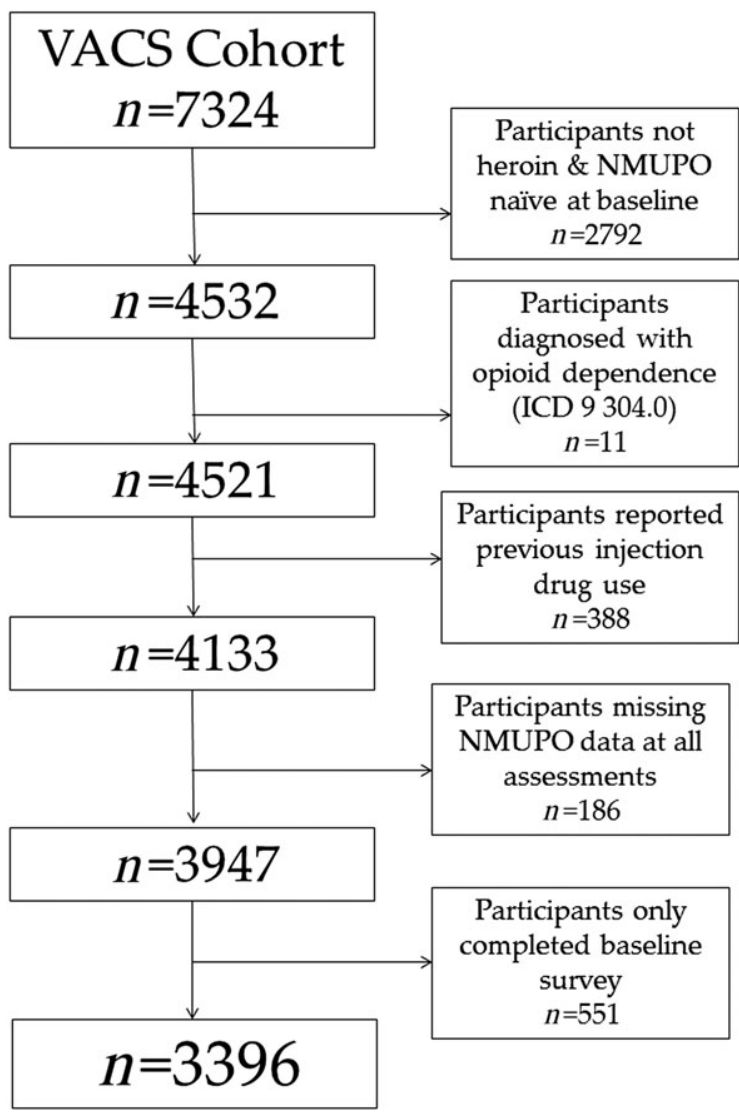

Figure I Flow-chart of eligible Veterans Aging Cohort Study (VACS) participants, 2002-12 NMUPO = non-medical use of prescription opioids 
eligible VACS participants, 2792 (38.1\%) were excluded, as they reported 'yes' to ever using a prescription opioid non-medically or heroin use at baseline. Of these participants, we excluded those who reported any injection drug use at baseline, or who were previously diagnosed with opioid dependence based on linked EMR records (ICD-9 code 304.0) $(n=399)$. Finally, we excluded participants who were missing or had invalid NMUPO and heroin use responses in all five follow-up surveys $(n=186)$ or only completed the baseline survey $(n=551)$. Using data from the VHA Patient Treatment File, the Beneficiary Identification Records Locating System (which tracks VHA death benefits, the Medicare Vital Status file and the Social Security National Death index, we identified 203 (36.9\%) deaths among those participants who only completed the baseline survey. We compared the characteristics of those who did not complete at least one follow-up visit due to death or other reasons with those who were eligible (see Supporting information). We accounted for biases arising from potential differential loss to follow-up in weighted statistical analyses (see below). The final analytical sample consisted of 3396 veterans.

\section{Measures}

We operationalized the main exposure of NMUPO using responses to two different survey questions. In the first two of five survey waves, participants were shown a list of the following substances: 'marijuana, cocaine/crack, stimulants, heroin, and prescription opioids (morphine, codeine, Vicodin, Percocet, OxyContin)', and asked: 'For each of the following drugs, please fill in the oval that best indicates how often in the past 12 months you have used each drug'. Those participants who reported any use of prescription opioids were categorized as reporting NMUPO. In the final three follow-up survey waves participants were asked: "Now think only about the past 12 months. On average, how many days each week in the past 12 months did you use any prescription pain reliever that was not prescribed for you or that you took only for the experience or feeling that it caused?' [32]. Again, participants reporting any frequency of use were categorized as reporting NMUPO. Participants who experienced the outcome of interest (i.e. heroin initiation) in the same year that they initiated NMUPO were included in the analysis; thus, new-onset NMUPO was considered to occur prior to or concurrently with heroin initiation.

Self-reported heroin initiation was ascertained based on respondent endorsement of following time-updated survey item: 'How often in the past year have you used each drug -heroin?'. A heroin initiation event was defined as change in respondent's answer to the previous survey question, from 'Never' to a response indicating some frequency of heroin use in the previous year.
Selection of other independent variables and potential confounders of the relationship between NMUPO and heroin initiation were chosen for analysis based on the extant literature [22,28,33-36]. Demographic and clinical characteristics were ascertained from the baseline survey data and included age, sex, race, marital status and gross annual income. HIV status was identified using VA Immunology Case Registry and hepatitis $C$ virus status was determined using ICD-9 codes and laboratory data. Previous post-traumatic stress disorder (PTSD) and depression diagnoses were ascertained from the following questions: 'Has the doctor ever told you that you have PTSD?' and 'Has the doctor ever told you that you have depression?'. Pain interference in daily life was ascertained from responses to the following time-updated survey item: 'During the past 4 weeks, how much did pain interfere with your normal work (including both work outside the home and housework)?' [37]. The response options for this question included a scale from 'not at all' to 'extremely', which we dichotomized into 'no interference' ('not at all') and 'any interference' (any other response). Past-year use of marijuana, cocaine and methamphetamines was dichotomized as yes/no. Alcohol use was characterized using the Alcohol Use Disorders Identification Test (AUDIT); a score of 4 and above indicated unhealthy alcohol use for men, and a threshold of 3 for women [38]. Responses to questions regarding substance use (including marijuana, cocaine and methamphetamines), unhealthy alcohol use, prior PTSD and depression diagnoses and pain interference in daily life were updated at each survey and were considered time-dependent covariates. Consistent with prior methods, receipt of outpatient prescribed opioids from the VHA was ascertained from linked pharmacy records, and long-term prescription opioid use was defined as $\geq 90$ days of continuous use allowing for a 30-day gap between fill and refill $[27,29,39]$. We created a time-updated variable for past-year receipt of prescription opioids for each wave of data, and categorized it into 'none', 'short-term' and 'long-term'.

\section{Statistical analyses}

First, we used $\chi^{2}$ tests to examine the baseline correlates of heroin initiation. Additionally, in a post-hoc analysis, we examined interaction terms between NMUPO and race. Next, unadjusted Kaplan-Meier analysis and the log-rank test were used to calculate the incidence of heroin initiation and compare time to heroin use, stratifying by prior or concurrent NMUPO.

To analyze the factors associated with heroin initiation, we used Cox proportional hazards regression to estimate crude hazard ratios (CHRs) and 95\% confidence intervals (CI) for each variable. To determine the independent 
relationship between new-onset NMUPO and heroin initiation, we then constructed a multivariable Cox model, including all variables assessed in bivariable analyses. All variables were found to meet the proportional hazards assumption for the Cox regression models (i.e. none exhibited significant deviance from this assumption at $P<0.05)$ [40].

We created inverse probability of censoring weights (IPCWs) to account for potential biases arising from differential dropout [41]. The use of IPCW re-weights the sample such that the contribution of participants who remain in the study, but who share characteristics of those who drop out, are inflated [42]. Weights were obtained through fitting a weighted pooled logistic regression model for dropout, including baseline and time-varying predictors of dropping out. We included a robust sandwich estimator in all Cox regression models to account for potential clustering heterogeneity by study site [43]. Analyses were conducted using SAS version 9.4.

\section{Sensitivity analysis}

In order to assess the validity of our exclusion criteria and ensure that our sample was restricted to heroin-naive participants we re-ran the adjusted Cox regression model, excluding those participants who were HCV-positive at baseline ( $n=701)$, under the assumption that the majority could have contracted HCV via injecting.

\section{RESULTS}

\section{Sample composition}

The baseline demographic, clinical and substance use characteristics of the 3396 eligible VACS participants are described in Table 1. The mean age was 49.7 [standard deviation $(\mathrm{SD})=10.6], 2106(62.5 \%)$ were black and 327 (9.7\%) were Hispanic. Approximately 1500 participants (45\%) were HIV-infected. At baseline, 102 (3.8\%) participants had a past-year opioid prescription from the VHA. Table 1 describes the characteristics of participants who reported new-onset NMUPO during the study. Past-year stimulant and past-year cocaine use were associated significantly with NMUPO in our study sample $(P<0.05)$. However, receipt of a prescription opioid from the VHA was not associated significantly with NMUPO. There were no substantial differences between the distribution of baseline characteristics among those participants who did not complete at least one follow-up visit or were missing exposure data and those participants who were eligible for our study (see Supporting information, Table S1).

The mean proportion of participants who initiated or continued non-medical use of prescription opioids across all follow-up waves after baseline was $6.9 \%$. There was no clear secular trend in the proportion of participants who reported NMUPO over time (Mantel-Haenszel test for trend $P=0.208)$.

\section{Risk factors for heroin initiation}

Of the total sample, 500 (14.7\%) participants initiated heroin use during the 10-year study period. Being black, male, 43-49 years of age, less educated and having a lower income were associated significantly with heroin initiation (all $P<0.001$ ). Marijuana, cocaine, stimulant and unhealthy alcohol use in the past year were associated significantly with heroin initiation. (all $P<0.05$, see Table 2).

Figure 2 illustrates the Kaplan-Meier curves for time to heroin initiation, which differed significantly between participants who reported prior/concurrent NMUPO and non-users; the log-rank test was significant at $P<0.001$. Of the 500 heroin initiates, $77 \%$ reported previous or concurrent NMUPO $(P<0.001)$. The crude incidence rate for heroin initiation in our entire study sample was 2.60 per 100 person-years, while the crude incidence rate for heroin was 4.82 per 100 person-years among those reporting NMUPO and 1.02 per 100 person-years among non-users, respectively $(P<0.001)$. Of the participants who reported new-onset NMUPO, 27.3\% initiated heroin by the end of the 10-year study period. (see Supporting information, Figure S1), depicts the proportion initiating heroin use among participants who engaged in NMUPO at each time-point.

The results from both the unadjusted and adjusted Cox regression models using IPCW are shown in Table 3. The crude hazard for heroin initiation was significantly higher for males than for females, and the crude hazards for black and Hispanic participants were significantly higher than for white participants. Those participants with a previous PTSD or depression diagnoses had a significantly higher hazard of heroin initiation when compared to those without these diagnoses. The crude hazard ratios of heroin initiation among past-year marijuana, stimulant and cocaine users were also significantly higher than those participants who reported no use. For participants reporting concurrent or prior NMUPO versus none, the crude hazard ratio was 5.15 [95\% confidence interval $(\mathrm{CI})=3.89-6.81]$.

In the multivariable Cox regression analysis, NMUPO remained associated positively and significantly with heroin initiation [adjusted hazard ratio $(\mathrm{AHR})=5.43$, $95 \% \mathrm{CI}=4.01-7.35]$. In the fully adjusted and weighted model, those who reported stimulant use and cocaine use in the last year had AHRs of $2.12(95 \% \mathrm{CI}=1.05-4.27)$ and $1.74(95 \% \mathrm{CI}=1.10-2.76)$, respectively, compared to those participants who reported no past-year use. Receipt of a short-term opioid prescription from the VHA 
Table 1 Baseline characteristics associated with new-onset non-medical use of prescription opioids among veterans participating in Veterans Aging Cohort Study (VACS), 2002-12.

\begin{tabular}{|c|c|c|c|c|}
\hline \multirow[b]{2}{*}{ Characteristic } & \multirow[b]{2}{*}{ Total $(\%)(N=3396)$} & \multicolumn{2}{|l|}{ Reported NMUPO } & \multirow[b]{2}{*}{ P-value } \\
\hline & & Yes $(\%)(n=1416)$ & No $(\%)(n=1980)$ & \\
\hline \multicolumn{4}{|l|}{ Sex } & 0.468 \\
\hline Male & $3171(93.4)$ & $1317(41.5)$ & $1854(58.5)$ & \\
\hline Female & $225(6.6)$ & $99(44.0)$ & $126(56.0)$ & \\
\hline \multicolumn{4}{|l|}{ Age (years) } & 0.001 \\
\hline$\leq 42$ & $846(24.9)$ & $356(42.1)$ & $490(57.9)$ & \\
\hline $43-49$ & $880(25.9)$ & $387(44.0)$ & $493(56.0)$ & \\
\hline $50-56$ & $884(26.0)$ & $392(44.3)$ & $492(55.7)$ & \\
\hline$\geq 57$ & $786(23.1)$ & $281(35.8)$ & $505(64.2)$ & \\
\hline \multicolumn{4}{|l|}{ HIV } & $<0.001$ \\
\hline Yes & $1539(45.3)$ & $694(45.1)$ & $845(54.9)$ & \\
\hline No & $1857(54.7)$ & $722(38.9)$ & $1135(61.1)$ & \\
\hline \multicolumn{4}{|l|}{$\mathrm{HCV}$} & 0.034 \\
\hline Yes & $701(20.6)$ & $317(45.2)$ & $384(54.8)$ & \\
\hline No & $2695(79.4)$ & $1099(40.8)$ & $1596(59.2)$ & \\
\hline \multicolumn{4}{|l|}{ Race } & $<0.001$ \\
\hline White & $808(24.0)$ & $430(53.2)$ & $378(46.8)$ & \\
\hline Black & $2106(62.5)$ & $800(38.0)$ & $1306(62.0)$ & \\
\hline Hispanic & $327(9.7)$ & $106(32.4)$ & $221(67.6)$ & \\
\hline Other & $128(3.8)$ & $57(44.5)$ & $71(55.5)$ & \\
\hline \multicolumn{4}{|l|}{ Education } & 0.001 \\
\hline High school or less & $1301(38.3)$ & 499 (38.4) & $802(61.6)$ & \\
\hline Some college or greater & $2095(61.7)$ & $917(43.8)$ & $1178(56.2)$ & \\
\hline \multicolumn{4}{|l|}{ Gross annual income } & 0.711 \\
\hline$<\$ 6000$ & $532(16.2)$ & $220(41.4)$ & $312(58.7)$ & \\
\hline$\$ 6000-11999$ & $695(21.2)$ & $295(42.5)$ & $400(57.6)$ & \\
\hline$\$ 12000-24999$ & $856(26.1)$ & $344(40.2)$ & $512(59.8)$ & \\
\hline$\$ 25000-49999$ & $815(24.8)$ & $474(58.2)$ & $341(41.8)$ & \\
\hline$\geq \$ 50000$ & $383(11.7)$ & $170(44.4)$ & $213(55.6)$ & \\
\hline \multicolumn{4}{|l|}{ Marital status } & $<0.425$ \\
\hline Married/living with partner & $1128(33.5)$ & $481(42.6)$ & $647(57.4)$ & \\
\hline Divorced/separated/widowed & $1257(37.3)$ & $508(40.4)$ & $749(59.6)$ & \\
\hline Never married & $984(29.2)$ & $421(42.8)$ & $563(57.2)$ & \\
\hline \multicolumn{4}{|l|}{ Pain interference in daily life } & $<0.001$ \\
\hline Yes & $1966(58.2)$ & 955 (48.6) & $1011(51.4)$ & \\
\hline No & 1415 (41.9) & $457(32.3)$ & $958(67.7)$ & \\
\hline \multicolumn{4}{|l|}{ Opioid Rx, past year } & 0.330 \\
\hline None & $3265(96.1)$ & $1357(41.6)$ & $1908(58.4)$ & \\
\hline Short-term & $102(3.0)$ & $43(42.2)$ & $59(57.8)$ & \\
\hline Long-term & $29(0.9)$ & $16(55.2)$ & $13(44.8)$ & \\
\hline \multicolumn{4}{|l|}{ Marijuana use, past year } & 0.165 \\
\hline Yes & $654(19.3)$ & $289(44.2)$ & $365(55.8)$ & \\
\hline No & $2730(80.7)$ & $1125(41.2)$ & $1605(58.8)$ & \\
\hline \multicolumn{4}{|l|}{ Stimulant use, past year } & 0.012 \\
\hline Yes & $53(1.6)$ & $31(58.5)$ & $22(41.5)$ & \\
\hline No & $3341(98.4)$ & $1384(41.4)$ & $1957(58.6)$ & \\
\hline \multicolumn{4}{|l|}{ Cocaine use, past year } & $<0.024$ \\
\hline Yes & $421(12.5)$ & $197(46.8)$ & $224(53.2)$ & \\
\hline No & $2958(87.5)$ & $1213(41.0)$ & $1745(59.0)$ & \\
\hline \multicolumn{4}{|c|}{ Unhealthy alcohol use, past year (AUDIT-C score $\geq 3$ or 4 ) } & 0.239 \\
\hline Yes & $864(25.4)$ & $375(43.4)$ & $489(56.6)$ & \\
\hline No & $2532(74.6)$ & $1041(41.1)$ & $1491(58.9)$ & \\
\hline
\end{tabular}

${ }^{\mathrm{a}}$ From $\chi^{2}$ tests. HIV = human immunodeficiency virus; $\mathrm{HCV}$ = hepatitis $\mathrm{C}$ virus; AUDIT = Alcohol Use Disorders Identification Test; NMUPO = non-medical use of prescription opioids. 
Table 2 Baseline characteristics associated with heroin initiation among veterans participating in Veterans Aging Cohort Study (VACS), 2002-12.

\begin{tabular}{|c|c|c|c|c|}
\hline \multirow[b]{2}{*}{ Characteristic } & \multirow[b]{2}{*}{ Total $(\%)(N=3396)$} & \multicolumn{2}{|l|}{ Initiated heroin } & \multirow[b]{2}{*}{ P-value ${ }^{\mathrm{a}}$} \\
\hline & & Yes $(\%)(n=500)$ & No $(\%)(n=2896)$ & \\
\hline \multicolumn{4}{|l|}{ Sex } & $<0.001$ \\
\hline Male & $3171(93.4)$ & $487(15.4)$ & $2684(84.6)$ & \\
\hline Female & $225(6.6)$ & $13(5.8)$ & $212(94.2)$ & \\
\hline \multicolumn{4}{|l|}{ Age (years) } & $<0.001$ \\
\hline$\leq 42$ & $846(24.9)$ & 105 (12.4) & $741(87.6)$ & \\
\hline $43-49$ & $880(24.9)$ & $186(21.1)$ & $694(78.9)$ & \\
\hline $50-56$ & $884(26.0)$ & $138(15.6)$ & $746(84.4)$ & \\
\hline$\geq 57$ & $786(23.1)$ & $71(9.0)$ & $715(91.0)$ & \\
\hline \multicolumn{4}{|l|}{ HIV } & $<0.001$ \\
\hline Yes & $1539(45.3)$ & $279(18.1)$ & $1260(81.9)$ & \\
\hline No & $1857(54.7)$ & $221(11.9)$ & $1636(88.1)$ & \\
\hline \multicolumn{4}{|l|}{$\mathrm{HCV}$} & $<0.001$ \\
\hline Yes & $701(20.6)$ & $170(24.3)$ & $531(75.8)$ & \\
\hline No & $2695(79.4)$ & $330(12.2)$ & $2365(87.8)$ & \\
\hline \multicolumn{4}{|l|}{ Race } & $<0.001$ \\
\hline White & $808(24.0)$ & $76(9.4)$ & $732(90.6)$ & \\
\hline Black & $2106(62.5)$ & $363(17.2)$ & $1743(82.8)$ & \\
\hline Hispanic & $327(9.7)$ & $38(11.6)$ & $289(88.4)$ & \\
\hline Other & $128(3.8)$ & $22(17.2)$ & $106(82.8)$ & \\
\hline \multicolumn{4}{|l|}{ Education } & $<0.001$ \\
\hline High school or less & $1301(38.3)$ & $235(18.1)$ & $1066(81.9)$ & \\
\hline Some college or greater & 2095 (61.7) & $265(12.7)$ & $1830(87.3)$ & \\
\hline \multicolumn{4}{|l|}{ Gross annual income } & $<0.001$ \\
\hline$<\$ 6000$ & $532(16.2)$ & $116(21.8)$ & $416(78.2)$ & \\
\hline$\$ 6000-11999$ & $695(21.2)$ & $128(18.4)$ & $567(81.6)$ & \\
\hline$\$ 12000-24999$ & $856(26.1)$ & $119(13.9)$ & $737(86.1)$ & \\
\hline$\$ 2500-49999$ & $815(24.8)$ & $94(11.5)$ & $721(88.5)$ & \\
\hline$\geq \$ 50000$ & $383(11.7)$ & $28(7.3)$ & $355(92.7)$ & \\
\hline \multicolumn{4}{|l|}{ Marital status } & $<0.001$ \\
\hline Married/living with partner & $1128(33.5)$ & $126(11.2)$ & $1002(88.8)$ & \\
\hline Divorced/separated/widowed & $1257(37.3)$ & $200(15.9)$ & $1057(84.1)$ & \\
\hline Never married & $984(29.2)$ & $171(17.4)$ & $813(82.6)$ & \\
\hline \multicolumn{4}{|l|}{ Pain interference in daily life } & 0.115 \\
\hline Yes & $1966(58.2)$ & $305(15.5)$ & $1661(84.5)$ & \\
\hline No & 1415 (41.9) & $192(13.6)$ & $1223(86.4)$ & \\
\hline \multicolumn{4}{|l|}{ Opioid Rx, past year } & 0.565 \\
\hline None & $3265(96.1)$ & $481(14.7)$ & $2784(85.3)$ & \\
\hline Short-term & $102(3.0)$ & $13(12.8)$ & $89(87.2)$ & \\
\hline Long-term & $29(0.9)$ & $6(20.7)$ & $23(79.3)$ & \\
\hline \multicolumn{4}{|l|}{ Marijuana use, past year } & $<0.001$ \\
\hline Yes & $654(19.3)$ & $126(19.3)$ & $528(80.7)$ & \\
\hline No & $2730(80.7)$ & $373(13.7)$ & $2357(86.3)$ & \\
\hline \multicolumn{4}{|l|}{ Stimulant use, past year } & 0.005 \\
\hline Yes & $53(1.6)$ & $15(28.3)$ & $38(71.7)$ & \\
\hline No & $3341(98.4)$ & $485(14.5)$ & $2856(85.5)$ & \\
\hline \multicolumn{4}{|l|}{ Cocaine use, past year } & $<0.001$ \\
\hline Yes & $421(12.5)$ & $144(34.2)$ & $277(65.8)$ & \\
\hline No & $2958(87.5)$ & $354(12.0)$ & $2604(88.0)$ & \\
\hline \multicolumn{4}{|c|}{ Unhealthy alcohol use, past year (AUDIT-C score $\geq 3$ or 4 ) } & 0.006 \\
\hline Yes & $864(25.4)$ & $152(17.6)$ & $712(82.4)$ & \\
\hline No & $2532(74.6)$ & $348(13.7)$ & $2184(86.3)$ & \\
\hline
\end{tabular}

${ }^{\mathrm{a}}$ From $\chi^{2}$ tests; HIV = human immunodeficiency virus; $\mathrm{HCV}=$ hepatitis $\mathrm{C}$ virus; AUDIT = Alcohol Use Disorders Identification Test. 
Figure 2 Relationship between prior/concurrent non-medical use of prescription opioids (NMUPO) and first-time initiation of heroin among Veterans Aging Cohort Study (VACS) participants (2002-12)

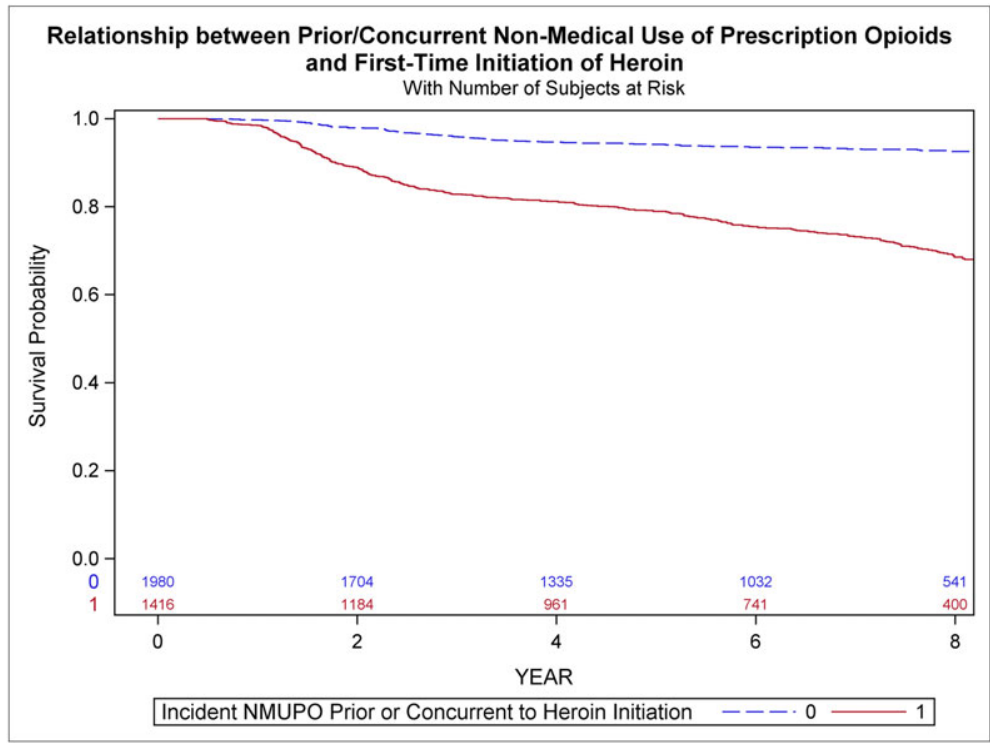

increased the hazard of heroin initiation by $65 \%$ $(\mathrm{AHR}=1.65,95 \% \mathrm{CI}=1.43-1.94)$ in our fully adjusted model. Other factors associated independently with heroin initiation are shown in Table 3. In post-hoc analyses, the effect of NMUPO on heroin initiation varied significantly by race: $\mathrm{AHR}=5.46,95 \% \mathrm{CI}=3.72-8.02$ for black participants, $\mathrm{AHR}=7.67,95 \% \mathrm{CI}=4.23-13.88$ for Hispanic participants and AHR $=4.89$, 95\% $\mathrm{CI}=2.52-9.37$ for white participants.

\section{Sensitivity analysis}

After removing the 701 (20.6\%) HCV-infected participants, the association between NMUPO and heroin initiation remained similar to that in the original model. Specifically, NMUPO had an AHR of 6.21 (95\% $\mathrm{CI}=4.54-8.51)$.

\section{DISCUSSION}

In this study, we characterized the relationship between new-onset NMUPO and heroin initiation in a population of US military veterans receiving medical care in the VHA. Our results indicate a strong association between prior or concurrent NMUPO and initiation of heroin use. The observed effect was robust to covariate adjustment and a sensitivity analysis. To our knowledge, this study is the first to demonstrate an effect of NMUPO on risk for heroin initiation prospectively among veterans receiving medical care.

Given these findings, it is important for clinicians to be cognizant of risk factors that are associated with transitioning to heroin initiation among veterans and other high-risk populations. Our results, corroborated by other literature $[12,44,45]$, indicate that being a racial minority, having lower education and income levels and reporting other substance use (particularly cocaine, stimulant and alcohol use) are all associated with heroin initiation. HIV and HCV infection were both predictors of heroin initiation in our fully adjusted model. This is cause for concern, as the transmission of infectious diseases may occur as a result of initiation of injection of heroin or prescription opioids [46]. Finally, the differences in the effect of NMUPO on heroin initiation between black, white and Hispanic participants may be due to disparities in access to appropriate pain management and/or reduced access to opioid prescriptions among minorities [47]. Future research is needed to explore further the role of reduced access to prescription opioids as a risk factor for heroin initiation in minority populations.

Our study suggests that the identification and treatment of non-medical prescription opioid use in a veteran population could be an important strategy for preventing heroin initiation. Guidelines, including those developed by the Department of Veterans Affairs and Department of Defense, recommend that prescribers of long-term opioids re-assess treatment effectiveness, adverse effects and adherence to therapy regularly; monitor for evidence of opioid misuse or substance abuse; and consider written treatment agreements and periodic urine drug testing [48]. It is important that continued attention be given to the development and refinement of screening procedures to identify problematic prescription opioid use among veterans receiving care.

Our study eligibility criteria resulted in the exclusion of a number of participants with opioid prescriptions from the VHA. For example, participants who reported any injection drug use and participants who had a previous diagnosis of an opioid dependence at baseline were excluded, both of which are factors associated with prescription opioid 
Table 3 Inverse probability weighted Cox proportional hazard model of factors associated with time to self-reported incident heroin use among non-medical use of prescription opioids (NMUPO)/heroin-naïve veterans participating in Veterans Aging Cohort Study (VACS), $2002-12^{\mathrm{d}}$.

\begin{tabular}{|c|c|c|c|c|}
\hline Characteristic & Unadjusted HR ${ }^{\mathrm{d}}(95 \%$ CI) & $P$ - value & Adjusted $\mathrm{HR}^{\mathrm{d}}(95 \% \mathrm{CI})$ & $P$ - value \\
\hline NMUPO (any NMUPO versus none) ${ }^{c}$ & $5.15(3.89-6.81)$ & $<0.001$ & $5.43(4.01-7.35)$ & $<0.001$ \\
\hline Sex (ref: Female) ${ }^{\mathrm{b}}$ & $2.91(1.18-7.19)$ & 0.021 & $2.61(1.08-6.29)$ & 0.033 \\
\hline \multicolumn{5}{|l|}{ Age (ref: $\leq 42$ years) ${ }^{b}$} \\
\hline 43-49 years & $1.79(1.56-2.07)$ & $<0.001$ & $1.67(1.44-1.93)$ & $<0.001$ \\
\hline $50-6$ years & $1.36(1.20-1.53)$ & $<0.001$ & $1.33(1.16-1.52)$ & $<0.001$ \\
\hline$\geq 57$ years & $0.76(0.54-1.05)$ & 0.093 & $0.95(0.64-1.42)$ & 0.817 \\
\hline HIV (infected versus uninfected) ${ }^{b}$ & $1.65(1.44-1.89)$ & $<0.001$ & $1.17(1.04-1.32)$ & 0.012 \\
\hline HCV (infected versus uninfected) ${ }^{b}$ & $2.19(1.63-2.95)$ & $<0.001$ & $1.46(1.24-1.72)$ & $<0.001$ \\
\hline \multicolumn{5}{|l|}{ Race (ref: white) ${ }^{\mathrm{b}}$} \\
\hline Black & $1.88(1.42-2.49)$ & $<0.001$ & $1.95(1.46-2.61)$ & $<0.001$ \\
\hline Hispanic & $1.39(1.08-1.79)$ & 0.010 & $1.49(1.09-2.03)$ & 0.011 \\
\hline Other & $2.18(1.85-2.57)$ & $<0.001$ & $1.86(1.49-2.30)$ & $<0.001$ \\
\hline \multicolumn{5}{|l|}{ Education (ref: high school or less) ${ }^{b}$} \\
\hline Some college or greater & $0.67(0.61-0.75)$ & $<0.001$ & $0.72(0.59-0.87)$ & $<0.001$ \\
\hline \multicolumn{5}{|l|}{ Gross annual income $(\text { ref: }<\$ 6000)^{\mathrm{b}}$} \\
\hline$\$ 6000-11999$ & $0.79(0.59-1.07)$ & 0.131 & $1.01(0.74-1.37)$ & 0.956 \\
\hline$\$ 12000-24999$ & $0.58(0.49-0.67)$ & $<0.001$ & $0.88(0.71-1.10)$ & 0.268 \\
\hline$\$ 25000-49999$ & $0.50(0.35-0.70)$ & $<0.001$ & $0.78(0.63-0.97)$ & 0.028 \\
\hline$\geq \$ 50000$ & $0.28(0.16-0.49)$ & $<0.001$ & $0.52(0.30-0.90)$ & 0.019 \\
\hline \multicolumn{5}{|l|}{ Marital status (ref: married/living with partner) ${ }^{\mathrm{b}}$} \\
\hline Divorced/separated/widowed & $1.50(1.19-1.90)$ & $<0.001$ & $1.14(0.86-1.51)$ & 0.363 \\
\hline Never married & $1.74(1.32-2.31)$ & $<0.001$ & $1.36(0.99-1.86)$ & 0.061 \\
\hline PTSD (ever diagnosis versus none) ${ }^{\mathrm{a}}$ & $1.70(1.43-2.03)$ & $<0.001$ & $1.25(1.02-1.54)$ & 0.031 \\
\hline Depression (ever diagnosis versus none) ${ }^{\mathrm{a}}$ & $1.42(1.16-1.72)$ & $<0.001$ & $0.99(0.80-1.24)$ & 0.951 \\
\hline Pain interference in daily life (any versus none) ${ }^{\mathrm{a}}$ & $1.26(0.98-1.63)$ & 0.075 & $0.85(0.65-1.12)$ & 0.254 \\
\hline \multicolumn{5}{|l|}{ Opioid Rx (ref: none) $)^{\mathrm{a}}$} \\
\hline Short term & $1.44(1.08-1.93)$ & 0.012 & $1.65(1.43-1.90)$ & $<0.001$ \\
\hline Long term & $1.06(0.85-1.34)$ & 0.601 & $1.00(0.68-1.48)$ & 0.996 \\
\hline Unhealthy alcohol use, past year (AUDIT-C score $\geq 3$ or 4$)^{a}$ & $1.18(0.97-1.44)$ & 0.093 & $1.04(0.85-1.29)$ & 0.688 \\
\hline Marijuana use, past year (ref: none) ${ }^{\mathrm{a}}$ & $1.34(1.14-1.56)$ & $<0.001$ & $0.85(0.66-1.09)$ & 0.207 \\
\hline Cocaine use, past year (ref: none) $)^{\mathrm{a}}$ & $2.94(2.23-3.87)$ & $<0.001$ & $1.74(1.10-2.76)$ & 0.019 \\
\hline Stimulant use, past year (ref: none) ${ }^{\mathrm{a}}$ & $5.00(3.19-7.83)$ & $<0.001$ & $2.12(1.05-4.27)$ & 0.036 \\
\hline
\end{tabular}

aTime-updated covariates; ${ }^{\text {bat baseline; }}$ 'any report of new-onset NMUPO prior or concurrent to heroin initiation or censoring;. ${ }^{\mathrm{d}}$ using robust sandwich estimator HIV = human immunodeficiency virus; HCV = hepatitis C virus; $\mathrm{PTSD}=$ post-traumatic stress disorder; AUDIT = Alcohol Use Disorders Identification Test; $\mathrm{HR}=$ hazard ratio; $\mathrm{CI}=$ confidence interval.

receipt in the VACS sample [39]. For this reason, the proportion of the study sample who received an opioid prescription may be lower than the prevalence of opioid prescriptions in other VA populations, which averaged approximately $7.7 \%$, with a range of $0.26-21.8 \%$ in 2012 [49].

None the less, the finding that receipt of a short-term opioid prescription was associated independently with an increased hazard of heroin initiation adds to the literature demonstrating a strong correlation between therapeutic exposure to opioid analgesics and their abuse [50] Collectively, these results supported recently published CDC guidelines recommending that, when opioids are used to treat acute pain, physicians should prescribe no greater quantity than needed for the expected duration of the severe pain [51] These strategies may also reduce the total volume of diverted opioids for non-medical use. Finally, our findings suggest that clinicians should evaluate risk factors for heroin initiation (e.g. history of a substance use disorder) prior to initiating opioid therapy. The potential to reduce NMUPO and subsequent opioid use disorders and heroin use by reducing the prescribing of opioids is an especially important consideration for those countries where opioid prescribing is rising. If the rates of opioid prescribing and NMUPO continue to increase in Europe, future regulatory responses may be needed to prevent rates of opioid misuse that are seen in North America [52,53].

Our study had a number of limitations. First, our results may not be generalizable to all veterans receiving care in the VHA. Due to its design, the study enrolled individuals who are probably at higher risk for heroin initiation than the general veteran population (e.g. those with HIV 
and/or HCV infection). Notably, the rate of heroin initiation observed in this study, even among those non-exposed to NMUPO (1.0 per 100 person-years) is higher than the rate observed among US adults ( 0.11 per 100 person-years in 2011) [15] Future work is needed to examine the rate of heroin use and initiation among lower-risk populations of veterans and veterans not receiving care in the VHA. Another major limitation of this study was the fact that there were different versions of the survey question assessing non-medical use of prescription opioid use. To mitigate potential information bias arising from the fact that participants may have misunderstood the question in the first two versions of the survey (as referring to medical use of prescription opioids), we adjusted for receipt of an opioid prescription in all analyses. Thirdly, as with any survey questions reporting on substance use behaviors, it is likely that participants under-reported their previous heroin and NMUPO. We attempted to address this issue by excluding participants who reported previous injection drug use and those with an ICD-9 code for opioid dependence, as well as running sensitivity analyses excluding participants with hepatitis C. Additionally, we were able to ascertain only new-onset NMUPO concurrent or prior to heroin initiation. Finally, differential loss to follow-up was a potential source of bias in this study. This was addressed by using inverse probability of censoring weights to account for possible biases arising from differential loss to follow-up.

Despite these limitations, our study fills an important gap in the literature by comparing the demographic, clinical and substance use characteristics associated with heroin initiation among US veterans receiving medical care in the VHA. Identifying why particular veterans engage in NMUPO, and why a proportion of them then transition to heroin initiation, are possible next steps in developing effective NMUPO screening strategies. For example, previous studies involving college students have found that the single leading reason for non-medical use was to relieve pain [54-57]. However, in our final model, pain interference in daily life was not a significant predictor of heroin initiation. Given that the experiences and the demographics of a veteran population are substantially different from young college students, further research needs to be conducted in order to elucidate motivations for NMUPO among veterans who receive medical care in the VHA. In sum, recognizing that NMUPO is a strong risk factor for heroin initiation suggests the urgent need for improved screening and assessment.

\section{Declaration of interests}

None.

\section{Acknowledgements}

This work was supported by grants from the National Institute on Alcohol Abuse and Alcoholism (NIAAA: U10-AA013566, U01-AA020795, U01-AA020790, U24-AA020794, U10-AA013566, and P01AA019072), the National Institute of Allergy and Infectious Diseases (P30-AI042853), and in kind by the US Department of Veterans Affairs. J.R.G. is supported by the National Institute on Drug Abuse (F31-DA035567). E.J.E. is a Yale-Drug Abuse, Addiction, and HIV research scholar (K12-DA033312). B.D.L.M. is supported by the National Institute on Drug Abuse (R03-DA037770). S.S. M. is supported by the National Institute on Drug Abuse (R01-DA037866). S.C. is supported by AHRQ awards 1U19HS021112 and R18-HSO23258. R.D.K. is supported by a Center of Innovation grant from the Health Services Research and Development Service of the Department of Veterans Affairs (CIN 13-047). The sponsors had no role in the study design; the collection, analysis and interpretation of data; the writing of the report; and in the decision to submit the article for publication. We would like to acknowledge the veterans who participate in the Veterans Aging Cohort Study (VACS) and the study coordinators and staff at each VACS site and at the West Haven Coordinating Center. We would also like to thank Melissa Skanderson for her assistance and support during data acquisition. The views expressed in this paper are those of the authors and do not necessarily reflect the position or policy of the Department of Veterans Affairs.

\section{References}

1. Volkow ND. What science tells us about opioid abuse and addiction. Testimony before House Committee on Energy and Commerce, Subcommittee on Oversight and Investigations. Bethedsa, MD: National Institute on Drug Abuse; 2015.

2. Hedegaard H., Chen L.-H., Warner M. Drug-poisoning Deaths Involving Heroin: United States, 2000-2013. Hyattsville, MD: National Center for Health Statistics; 2015.

3. Unick G. J., Rosenblum D., Mars S., Ciccarone D. Intertwined epidemics: national demographic trends in hospitalizations for heroin- and opioid-related overdoses, 1993-2009. PLOS ONE 2013; 8: e54496.

4. Manchikanti L., Fellow B., Ailinani H., Pampati V. Therapeutic use, abuse, and nonmedical use of opioids: a ten-year perspective. Pain Physician 2010; 13: 401-35.

5. Fischer B., Keates A., Buhringer G., Reimer J., Rehm J. Nonmedical use of prescription opioids and prescription opioidrelated harms: why so markedly higher in North America compared to the rest of the world? Addiction 2014; 109: 177-81.

6. Substance Abuse and Mental Health Services (SAMHSA) Results from the 2012 National Survey on Drug Use and Health: Summary of National Findings. Rockville, MD: SAMHSA; 2014.

7. Joranson D., Ryan K., Gilson A., Dahl J. Trends in medical use and abuse of opioid analgesics. JAMA 2000; 283: 1710-14. 
8. Gilson A. M., Ryan K. M., Joranson D. E., Dahl J. L. A reassessment of trends in the medical use and abuse of opioid analgesics and implications for diversion control: 1997-2002. J Pain Symptom Manage 2004; 28: 176-1-8.

9. Paulozzi L, Franklin G, Kerlikowske R, Jones C, Ghiya N, Popovic T. Prescription Drug Overdoses-a US Epidemic. Bethesda, MD: Centers for Disease Control and Prevention; 2012.

10. Voon P., Callon C., Nguyen P., Dobrer S., Montaner J. S., Wood E. et al. Denial of prescription analgesia among people who inject drugs in a Canadian setting. Drug Alcohol Rev 2015; 34: $221-2218$.

11. van Amsterdam J., Phillips L., Henderson G., Bell J., Bowden-Jones O., Hammersley R. et al. Ranking the harm of non-medically used prescription opioids in the UK. Regul Toxicol Pharmacol 2015; 73: 999-1004.

12. Peavy K. M., Banta-Green C. J., Kingston S., Hanrahan M., Merrill J. O., Coffin P. O. 'Hooked on' prescription-type opiates prior to using heroin: results from a survey of syringe exchange clients. J Psychoact Drugs 2012; 44: 259-65.

13. Cicero T. J., Ellis M. S., Surratt H. L., Kurtz S. P. The changing face of heroin use in the United States: a retrospective analysis of the past 50 years. JAMA Psychiatry 2014; 71: 821-6.

14. Jones C. M. Heroin use and heroin use risk behaviors among nonmedical users of prescription opioid pain relievers -United States, 2002-2004 and 2008-2010. Drug Alcohol Depend 2013; 132: 95-100.

15. Muhuri P. K., Gfroerer J. C., Davies M. C. Associations of Nonmedical Pain Reliever Use and Initiation of Heroin Use in the United States. Rockville, MD: National Institute on Drug Abuse; 2013.

16. Irish C., Maxwell R., Dancox M., Brown P., Trotter C., Verne J. et al. Skin and soft tissue infections and vascular disease among drug users, England. Emerg Infect Dis 2007; 13: 1510-1.

17. Dart R. C., Surratt H. L., Cicero T. J., Parrino M. W., Severtson S. G., Bucher-Bartelson B. et al. Trends in opioid analgesic abuse and mortality in the United States. $N$ Engl J Med 2015; 372: 241-8.

18. Robins L. N., Helzer J. E., Hesselbrock M., Wish E. Vietnam veterans three years after Vietnam: how our study changed our view of heroin. Am J Addict 2010; 19: 203-11.

19. Bray R. M., Hourani L. L. Substance use trends among active duty military personnel: findings from the United States Department of Defense Health Related Behavior Surveys, 1980-2005. Addiction 2007; 102: 1092-101.

20. McFall M. E., Mackay P. W., Donovan D. M. Combat-related posttraumatic stress disorder and severity of substance abuse in Vietnam veterans. I Stud Alcohol 1992; 53: 357-63.

21. Lew H. L., Otis J. D., Tun C., Kerns R. D., Clark M. E., Cifu D. X. Prevalence of chronic pain, posttraumatic stress disorder, and persistent postconcussive symptoms in OIF/OEF veterans: polytrauma clinical triad. J Rehabil Res Dev 2009; 46: 697 .

22. Golub A., Bennett A. S. Prescription opioid initiation, correlates, and consequences among a sample of $\mathrm{OEF} / \mathrm{OIF}$ military personnel. Subst Use Misuse 2013; 48: 811-20.

23. Seal K. H., Shi Y., Cohen G., Cohen B. E., Maguen S., Krebs E. E. et al. Association of mental health disorders with prescription opioids and high-risk opioid use in US veterans of Iraq and Afghanistan. JAMA 2012; 307: 940-7.

24. Robins L. N. Vietnam veterans' rapid recovery from heroin addiction: a fluke or normal expectation? Addiction 1993; 88: 1041-54.
25. Barry D. T., Goulet J. L., Kerns R. K., Becker W. C., Gordon A. J., Justice A. C. et al. Nonmedical use of prescription opioids and pain in veterans with and without HIV. Pain 2011; 152: 1133-8.

26. Green T. C., Kershaw T., Lin H., Heimer R., Goulet J. L., Kraemer K. L. et al. Patterns of drug use and abuse among aging adults with and without HIV: A latent class analysis of a US Veteran cohort. Drug Alcohol Depend 2010; 110: 208-20.

27. Gaither J. R., Goulet J. L., Becker W. C., Crystal S., Edelman E. J., Gordon K. et al. Guideline-concordant management of opioid therapy among human immunodeficiency virus (HIV)-infected and uninfected veterans. J Pain 2014; 15: $1130-40$.

28. Edelman E. J., Gordon K., Becker W. C., Goulet J. L., Skanderson M., Gaither J. R. et al. Receipt of opioid analgesics by HIV-infected and uninfected patients. J Gen Intern Med 2013; 28: 82-90.

29. Weisberg D. F., Gordon K. S., Barry D. T., Becker W. C., Crystal S., Edelman E. J. et al. Long-term prescription of opioids and/or benzodiazepines and mortality among HIV-infected and uninfected patients. J Acquir Immune Defic Syndr 2015; 69: $223-3$.

30. Justice A. C., Dombrowski E., Conigliaro J., Fultz S. L., Gibson D., Madenwald T. et al. Veterans Aging Cohort Study (VACS): overview and description. Med Care 2006; 44 : S13-S124.

31. Justice A. C., Lasky E., McGinnis K. A., Skanderson M., Conigliaro J., Fultz S. L. et al. Medical disease and alcohol use among veterans with human immunodeficiency infection: a comparison of disease measurement strategies. Med Care 2006; 44: S52-S60.

32. Swartz J. A., Lurigio A. J. Screening for serious mental illness in populations with co-occurring substance use disorders: performance of the K6 scale. J Subst Abuse Treat 2006; 31 : 287-96.

33. Boscarino J. A., Rukstalis M., Hoffman S. N., Han J. J., Erlich P. M., Gerhard G. S. et al. Risk factors for drug dependence among out-patients on opioid therapy in a large US health-care system. Addiction 2010; 105: 1776-82.

34. Dobscha S. K., Morasco B. J., Duckart J. P., Macey T., Deyo R. A. Correlates of prescription opioid initiation and long-term opioid use in veterans with persistent pain. Clin J Pain 2013; 29: $102-8$.

35. Khosla N., Juon H. S., Kirk G. D., Astemborski J., Mehta S. H. Correlates of non-medical prescription drug use among a cohort of injection drug users in Baltimore City. Addict Behav 2011; 36: 1282-7.

36. Kolodny A., Courtwright D. T., Hwang C. S., Kreiner P., Eadie J. L., Clark T. W. et al. The prescription opioid and heroin crisis: a public health approach to an epidemic of addiction. Annu Rev Public Health 2015; 36: 559-74.

37. Salyers M. P., Bosworth H. B., Swanson J. W., Lamb-Pagone J., Osher F. C. Reliability and validity of the SF-12 health survey among people with severe mental illness. Med Care 2000; 38: 1141-50.

38. Bradley K. A., Bush K. R., Epler A. J., Dobie D. J., Davis T. M., Sporleder J. L. et al. Two brief alcohol-screening tests from the alcohol use disorders identification test (AUDIT). Arch Intern Med 2003; 163: 821-9.

39. Becker W. C., Gordon K., Jennifer Edelman E., Kerns R. D., Crystal S., Dziura J. D. et al. Trends in any and high-dose opioid analgesic receipt among aging patients with and without HIV. AIDS Behav 2016; 20: 679-86. 
40. Christensen E. Multivariate survival analysis using Cox's regression model. Hepatology 1987; 7: 1346-58.

41. Robins J. M., Finkelstein D. M. Correcting for noncompliance and dependent censoring in an AIDS clinical trial with inverse probability of censoring weighted (IPCW) log-rank tests. Biometrics 2000; 56: 779-88.

42. Cain L. E., Cole S. R. Inverse probability-of-censoring weights for the correction of time-varying noncompliance in the effect of randomized highly active antiretroviral therapy on incident AIDS or death. Stat Med 2009; 28: 1725-38.

43. Graubard B. I., Korn E. L. Regression analysis with clustered data. Stat Med 1994; 13: 509-22.

44. Lipari RN, Hughes A. The NSDUH report: trends in heroin use in the United States: 2002 to 2013. Rockville, MD: Substance Abuse and Mental Health Services Administration (SAMHSA); 2015.

45. Mars S. G., Bourgois P., Karandinos G., Montero F., Ciccarone D. 'Every "never" I ever said came true': transitions from opioid pills to heroin injecting. Int J Drug Policy 2014; 25: 257-66.

46. Guarino H., Marsch L. A., Deren S., Straussner S. L., Teper A. Opioid use trajectories, injection drug use, and hepatitis C virus risk among young adult immigrants from the former Soviet Union living in New York City. J Addict Dis 2015; 34: 162-77.

47. Ringwalt C., Roberts A. W., Gugelmann H., Skinner A. C. Racial disparities across provider specialties in opioid prescriptions dispensed to medicaide beneficiaries with chronic noncancer pain. Pain Med 2015; 16: 633-40.

48. Krebs E. E., Ramsey D. C., Miloshoff J. M., Blair M. J. Primary care monitoring of long-term opioid therapy among veterans with chronic pain. Pain Med 2011; 12: 740-6.

49. Healthcare Inspection. VA Patterns of Dispensing Take-Home Opioids and Monitoring Patients on Opioid Therapy 2014. Available at: http://www.va.gov/oig/pubs/VAOIG-14-00895163.pdf (7 June 2016).

50. Cicero T. J., Surratt H., Inciardi J. A., Munoz A. Relationship between therapeutic use and abuse of opioid analgesics in rural, suburban, and urban locations in the United States. Pharmacoepidemiol Drug Saf 2007; 16: 827-40.
51. Dowell D., Haegerich T. M., Chou R. CDC guideline for prescribing opioids for chronic pain-United States. Morb Mortal Wkly Rep 2016; 65: 1-49.

52. Voon P., Kerr T. Nonmedical' prescription opioid use in North America: a call for priority action. Subst Abuse Treat Prev Policy 2013; 8:39.

53. Weisberg D. F., Becker W. C., Fiellin D. A., Stannard C. Prescription opioid misuse in the United States and the United Kingdom: cautionary lessons. Int J Drug Policy 2014; 25: 1124-30.

54. McCabe S. E., Cranford J. A., Boyd C. J., Teter C. J. Motives, diversion and routes of administration associated with nonmedical use of prescription opioids. Addict Behav 2007; 32: $562-75$.

55. Sung H. E., Richter L., Vaughan R., Johnson P. B., Thom B. Nonmedical use of prescription opioids among teenagers in the United States: trends and correlates. J Adolesc Health 2005; 37: 44-51.

56. McCabe S. E., West B. T., Teter C. J., Boyd C. J. Medical and nonmedical use of prescription opioids among high school seniors in the United States. Arch Pediatr Adolesc Med 2012; 166: 797-802.

57. Boyd C. J., Young A., Grey M., McCabe S. E. Adolescents nonmedical use of prescription medications and other problem behaviors. J Adolesc Health 2009; 45: 543-50.

\section{Supporting Information}

Additional Supporting Information may be found in the online version of this article at the publisher's web-site:

Table S1 Baseline characteristics of eligible and excluded Veterans Aging Cohort Study (VACS) participants, 2002-012.

Figure S1 Proportion who initiated heroin use among participants reported current or prior non-medical use of prescription opioids (NMUPO), stratified by follow-up wave, Veterans Aging Cohort Study (VACS) (2002-12). 